\title{
CROMATOGRAFIA DE INTERAÇÕES MISTAS (MMC): ADSORÇÃO DE IMUNOGLOBULINA G (IgG) EM ORTO- FOSFO-L-TIROSINA (OPT)-AGAROSE
}

\author{
G. L. PAVAN ${ }^{1}$ e S.M.A.BUENO ${ }^{1}$ \\ ${ }^{1}$ Universidade Estadual de Campinas, Faculdade de Engenharia Química, Departamento de \\ Engenharia de Materiais e de Bioprocessos \\ E-mail para contato: gisapavan@feq.unicamp.br
}

\begin{abstract}
RESUMO - A captura de IgG por cromatografia utilizando aminoácidos e seus derivados como ligantes tem sido realizada com sucesso e em muito devido à diferentes interações (hidrofóbica, eletrostática, ligação $\pi-\pi$, etc) entre a proteína alvo e o ligante. A combinação de duas ou mais interações caracteriza a cromatografia de interações mistas (MMC), que tem proporcionado bons resultados na adsorção de IgG. Este trabalho visa o estudo da adsorção de $\operatorname{IgG}$ a partir do plasma humano em orto-fosfo-L-tirosina (OPT) imobilizado em agarose. Os resultados demonstraram que a interação entre IgG e o OPT é predominantemente eletrostática. Observou-se que o aumento do valor de $\mathrm{pH}$ diminuiu a capacidade de adsorção, no entanto, observou-se maior seletividade na adsorção de IgG. Homogeneidade eletroforética foi observada para os tampões Bis-Tris e Mops em pH 7,0 e 7,5, respectivamente.
\end{abstract}

\section{INTRODUÇÃO}

A cromatografia de interações mistas (Mixed-mode Chromatography - MMC) apresenta ampla diversidade de ligantes os quais exploram as funções combinadas de dois ou mais mecanismos de interação (hidrofóbica, eletrostática, ligação de hidrogênio, forças de van der Waals e ligação $\pi-\pi$ ) entre a fase estacionária e os solutos presentes na alimentação (McLaughlin, 1989; Zhao et al., 2009; Gangnon, 2012). Alguns adsorventes utilizados em cromatografia de afinidade, como por exemplo, os corantes (Zhang e Sun, 2001) e alguns aminoácidos como o triptofano (Naik et al., 2011), apresentam características de ligantes de interações mistas.

Resultados de trabalhos recentes têm indicado aminoácidos contendo cadeia lateral aromática ou contendo grupos iônicos livres na sua estrutura como potenciais ligantes para captura e/ou purificação de imunoglobulina G humana (IgG) (Bayramoglu et al., 2007; Turkmen et al., 2008; Victor e Sharma, 2011; Naik et al., 2011; Bresolin et al., 2011; Bresolin e Bueno, 2012). No caso de aminoácidos tais como lisina e orto-fosfo-L-serina (OPS) imobilizados, vários autores tem demonstrado que as forças que governam a adsorção são predominantemente de natureza eletrostática, embora outros tipos de contribuição não possam ser descartados (Bresolin et al., 2011; Bresolin e Bueno, 2012). Para o primeiro aminoácido citado, os grupamentos livres para interação com IgG encontram-se positivamente carregado em ampla faixa de $\mathrm{pH}$, sendo esta proteína obtida na fração de não retida ("flowthrough"), enquanto que o OPS encontra-se negativamente carregado, proporcionando 
a adsorção de IgG.

Embora aminoácidos sejam empregados como ligantes para purificação de $\operatorname{IgG}$ de diversas fontes, o efeito da contribuição dos diferentes grupos funcionais (iônicos e aromáticos) na adsorção de IgG ainda é não está completamente elucidado. Neste trabalho foi realizado um estudo para avaliar o efeito de grupamentos fosfato e aromáticos presentes na cadeia lateral do derivado de aminoácido orto-fosfo-L-tirosina (OPT), tendo como controle a fenetilamina (PEA), ambos imobilizados em gel de agarose por meio de um braço espaçador, o 1,4-butanodiol diglicil éter, a fim de determinar a contribuição dos diferentes grupamentos funcionais presentes na estrutura destes compostos na captura de $\operatorname{IgG}$ a partir de plasma humano utilizando a técnica de MMC.

\section{MATERIAIS E MÉTODOS}

\subsection{Materiais}

O gel de agarose 4B (Sepharose 4B, 4\% de reticulação, com diâmetro médio de partículas de 45 a $165 \mu \mathrm{m}$ e faixa de fracionamento de proteínas globulares de 60 a 20.000 $\mathrm{kDa}$ ), albumina de soro bovino, 1,4-butanodiol diglicil éter, comassie brilliant blue R-250, foram obtidos da Sigma-Aldrich (EUA). Acrilamida e bisacrilamida foram obtidas da BioRad (EUA). Azul de bromofenol, TEMED (N,N,N',N'-tetra-metilenodiamina), persulfato de amônio, SDS (dodecil sulfato de sódio), glicerol, ditiotrietol e kit de marcadores de massa molecular foram adquiridos da GE Healthcare (EUA). Os demais reagentes utilizados são todos de grau analítico. Foi utilizado água ultrapura Milli-Q (Millipore, EUA) para a preparação de todas as soluções.

Fluidos empregados: A IgG humana de alta pureza (95\% de pureza) foi adquirida da Sigma-Aldrich (EUA). Plasma humano de doadores sadios foi doado pelo Hemocentro da Universidade Estadual de Campinas (UNICAMP).

Ligantes propostos: Os ligantes OPT e PEA foram adquiridos da Sigma-Aldrich (EUA). A fórmula estrutural e os respectivos pKas dos ligantes propostos estão apresentados na Tabela 1.

Tabela 1: Fórmula estrutural e pKa dos ligantes estudados

\begin{tabular}{|c|c|c|}
\hline Ligante & Fórmula estrutural & $\mathbf{p K}_{\mathbf{a}}$ \\
\hline orto-fosfo-L-tirosina (OPT) & & $\begin{array}{c}<2 / 5,8 \text { (fosfato) } \\
2,4(-\mathrm{COOH}) \\
9,4\left(-\mathrm{NH}_{2}\right)\end{array}$ \\
\hline Feniletilamina (PEA) $)^{\mathrm{a}}$ & & $9,83\left(-\mathrm{NH}_{2}\right)$ \\
\hline
\end{tabular}

\footnotetext{
${ }^{\mathrm{a}}$ Ligante utilizado como controle
} 


\subsection{Métodos}

Ativação do gel: A ativação do gel de agarose 4B com 1,4 butanodiol diglicidil éter foi realizada conforme Hermanson et al.(1992). A um volume de $50 \mathrm{~mL}$ de gel úmido foi adicionado $40 \mathrm{~mL}$ de uma solução de $\mathrm{NaOH}$ a $0,6 \mathrm{~mol} \mathrm{~L}^{-1}$ contendo $75 \mathrm{mg}$ de borohidreto de sódio. Posteriormente, $40 \mathrm{~mL}$ de 1,4 butanodiol diglicil éter foi adicionado lentamente àquela suspensão, e mantida em agitação constante a temperatura ambiente por um período de 10 horas. Terminado o tempo de reação, o gel foi lavado com água destilada. O gel foi armazenado em solução de $\mathrm{NaCL}$ a $1,0 \mathrm{~mol} \mathrm{~L}^{-1}$ e sob refrigeração.

Imobilização dos ligantes: A imobilização dos ligantes OPT e PEA foi realizada de acordo com os protocolos apresentados por Zachariou et al. (1993). Para cada ligante foi preparada uma solução de $0,2 \mathrm{~mol} \mathrm{~L}^{-1}$ em água e o $\mathrm{pH}$ foi ajustado para 10,5 com pastilhas de $\mathrm{KOH}$ na temperatura de $4^{\circ} \mathrm{C}$. Para $15 \mathrm{~g}$ de gel ativado (base seca) foram adicionados $30 \mathrm{~mL}$ da solução contendo o ligante e esta suspensão ficou sob agitação por $4 \mathrm{~h}$, a $25^{\circ} \mathrm{C}$ (para ligante que contém fósforo) ou a $60^{\circ} \mathrm{C}$, durante $24 \mathrm{~h}$ (para ligantes que não contém fósforo), como recomendado por Zachariou et al. (1993). O gel contendo o ligante imobilizado foi lavado e, em seguida, suspenso em uma solução a $20 \%$ de etanol e mantido sob refrigeração até o uso.

Determinação da densidade de ligantes: a densidade de ligantes imobilizados foi determinada por análise elementar de nitrogênio, realizado na Central Analítica do Instituto de Química da Universidade de São Paulo (USP) utilizando o equipamento Perkin-Elmer CHN 2400 .

Ensaios cromatográficos: Os ensaios foram realizados utilizando os sistemas tamponantes MES, Bis-Tris, Mops e fosfato de sódio, em concentração de $25 \mathrm{mmol} \mathrm{L}^{-1}$, em valores de $\mathrm{pH}$ entre 5,5 e 7,5, na faixa tamponante de cada tampão. A coluna (modelo HR 5/10, GE Healthcare, EUA) foi preenchida com 1,0 mL de gel derivatizado com os ligantes propostos neste trabalho e conectada a um sistema de cromatografia de baixa pressão (ÄKTA Purifier, GE Healthcare, EUA). A coluna contendo o adsorvente foi equilibrada à temperatura ambiente com tampão de adsorção, citados anteriormente, a uma vazão de $1,0 \mathrm{~mL} \mathrm{~min}{ }^{-1}$. Soluções de $\operatorname{IgG}$ de alta pureza diluída no tampão de adsorção (concentração de $3,5 \mathrm{mg}$ $\mathrm{IgG} / \mathrm{mL}$, volume alimentado de $2,0 \mathrm{~mL}$ ) foram alimentados na coluna cromatográfica. A lavagem do adsorvente foi realizada na mesma vazão com o tampão de adsorção, visando a remoção das proteínas não adsorvidas ou adsorvidas fracamente. A eluição também foi realizada na mesma vazão, com a adição de $1,0 \mathrm{~mol} \mathrm{~L}^{-1}$ de $\mathrm{NaCl}$ no tampão de adsorção. A corrente de saída foi monitorada a $280 \mathrm{~nm}$ e as frações referentes a cada etapa cromatográfica foram coletadas. Para os ensaios com plasma foi escolhido as condições que apresentaram mais de $80 \%$ de adsorção de IgG de alta pureza, que foram, MES, Bis-Tris e Mops, em concentração de $25 \mathrm{mmol} \mathrm{L}^{-1}$, em valores de $\mathrm{pH}$ entre 5,5 e 7,5, na faixa tamponante de cada tampão. A solução de injeção foi preparada na concentração de aproximadamente $3 \mathrm{mg} \mathrm{mL}^{-1}$ e foi injetado $2 \mathrm{~mL}$ dessa solução. As frações de saída foram coletadas em volumes de 1,5 $\mathrm{mL}$. Ao término dos experimentos, o adsorvente foi regenerado com $50 \mathrm{mmol} \mathrm{L}^{-1}$ de $\mathrm{NaOH}$, e, em seguida, lavado com água e re-equilibrado com tampão de adsorção para ser re-utilizado em novo ciclo. 


\subsection{Métodos Analíticos:}

Dosagem de proteína total: A concentração de proteína total nas amostras foi determinada usando o método de Bradford (1976), com albumina do soro bovino e imunoglobulina $\mathrm{G}$ humana como proteína de referência, para os experimentos com plasma e IgG de alta pureza respectivamente.

Eletroforese SDS-PAGE: As frações protéicas obtidas nas etapas de adsorção, lavagem e eluição da cromatografia foram analisadas por eletroforese SDS-PAGE em gel a $7,5 \%$ em acrilamida em condições não redutoras. As amostras tratadas com SDS foram aquecidas a $100^{\circ} \mathrm{C}$ por $10 \mathrm{~min}$ e $10 \mu \mathrm{l}$ das amostras foram aplicadas nos géis. Os géis foram corados nitrato de prata de acordo com Morrissey (1981).

\section{RESULTADOS E DISCUSSÃO}

O OPT e PEA são derivados de aminoácidos que apresentam diferenças estruturais entre eles. O OPT apresenta um grupamento carboxílico e um grupamento fosfato ligado a um grupamento aromático, ambos livres, enquanto o PEA apresenta somente um grupamento aromático livre (Tabela 1). Os resultados obtidos para os testes realizados com IgG de alta pureza, para ambos ligantes, estão apresentados na Figura 1. A densidade de ligantes imobilizados no gel de agarose determinada pela análise elementar de nitrogênio é de 13,2 e $22,9 \mu \mathrm{mol} \mathrm{mL} \mathrm{m}^{-1}$ gel.
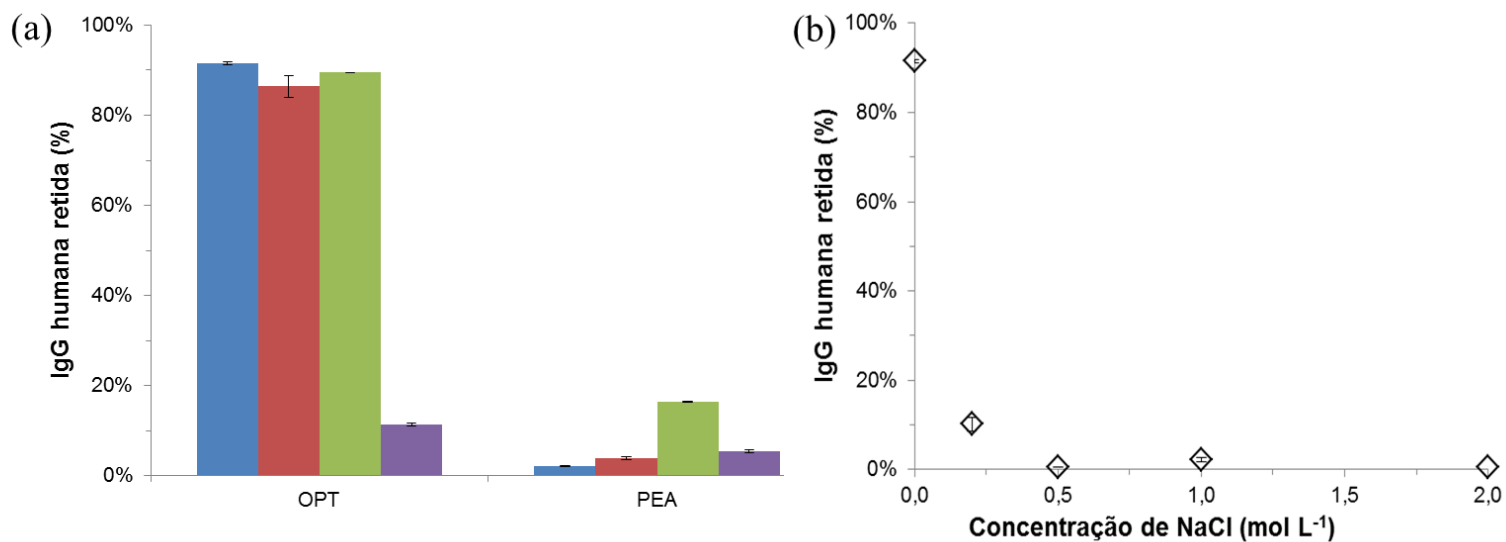

Figura 1: (a) Porcentagem de IgG adsorvida em OPT-agarose e PEA-agarose nos sistemas

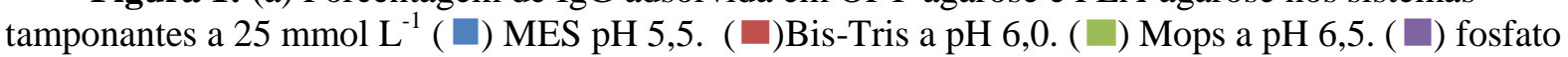
de sódio a pH 7,0. (b) Porcentagem de IgG retida em OPT-agarose no sistema tamponante MES pH 5,5 para as concentrações de $\mathrm{NaCl}$ entre 0,0 e $2,0 \mathrm{~mol} \mathrm{~L}^{-1}$.

O OPT apresentou maior porcentagem de retenção de IgG de alta pureza que o ligante PEA, tendo sido alcançado maior capacidade de adsorção para os sistemas tamponantes MES, Bis-Tris e Mops na faixa de pH estudada (Figura 1a), o que indica que a adsorção desta proteína é majoritariamente devido a contribuição dos grupamentos fosfatos e carboxílico e não do grupamento aromático presente na sua estrutura. A fim de estudar de forma preliminar a contribuição do grupamento fosfato e aromático na adsorção de IgG de alta pureza, foram 
realizados ensaios para o sistema tamponante MES variando a concentração de $\mathrm{NaCl}$ entre 0,0 e 2,0 mol L $\mathrm{L}^{-1}$. Os resultados apresentados na Figura $1 \mathrm{~b}$ demonstram que, como sugerido anteriormente, a adsorção ocorre predominantemente devido a interação eletrostática dos grupamentos fosfato e carboxílico com a IgG, uma vez que a capacidade de adsorção caiu drasticamente com o aumento da concentração do sal. A baixa capacidade de adsorção observada para o fosfato de sódio a $\mathrm{pH}$ 7,0 provavelmente esteja relacionada com a carga deste tampão, que é negativa, umas vez que o Mops e MES apresentam cargas de sinais opostos na sua estrutura (tampão zwiteriônico) e o Bis-Tris apresenta carga positiva.

Desta forma o adsorvente OPT-agarose foi selecionado para os testes com plasma humano. Para tais ensaio foram utilizados os sistemas tamponantes que proporcionaram mais de $80,0 \%$ de adsorção nos testes com IgG de alta pureza sendo eles, MES , Bis-Tris e Mops na faixa de $\mathrm{pH}$ entre 5,5 e 7,5. As Figuras 2 e 3 apresentam a capacidade de adsorção de proteína total nas condições citadas acima e o perfil eletroforético dos "pools" das etapas cromatográficas, respectivamente.

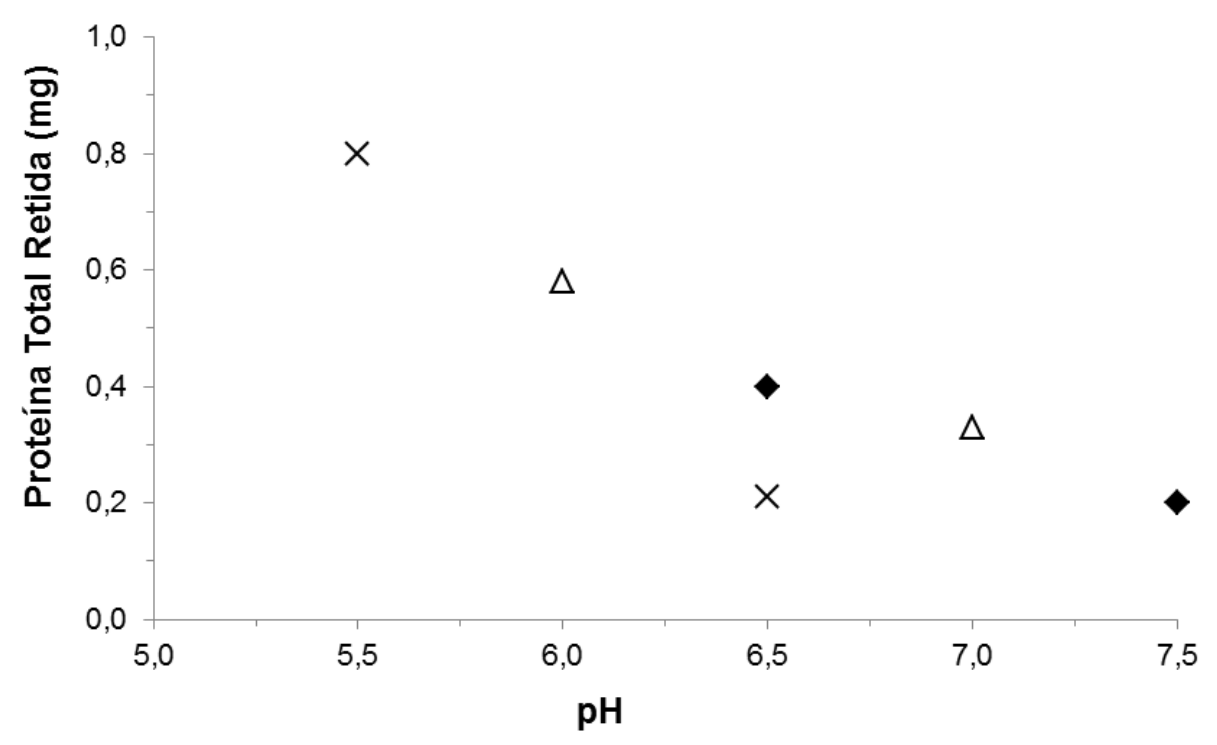

Figura 2: Capacidade de adsorção de proteína total $(\mathrm{mg})$ em função do $\mathrm{pH}$ empregado para os sistemas tamponantes $(\times) \operatorname{MES},(\Delta)$ Bis-Tris e $(\diamond)$ Mops. 
MES

(a)

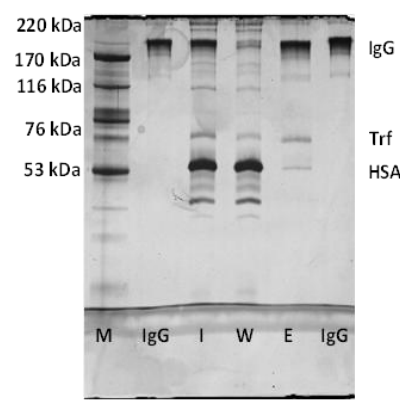

(b)

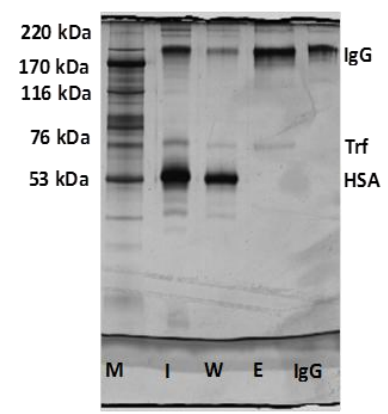

Mops

(c)

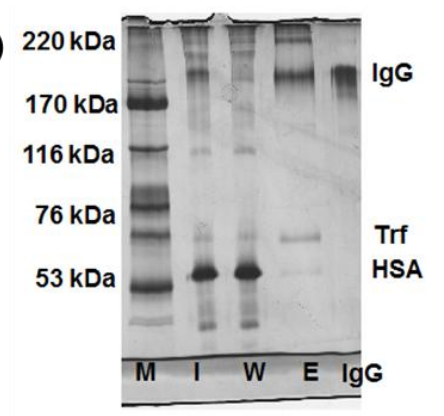

(d)

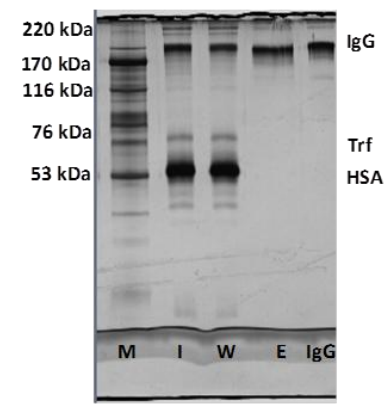

(e)

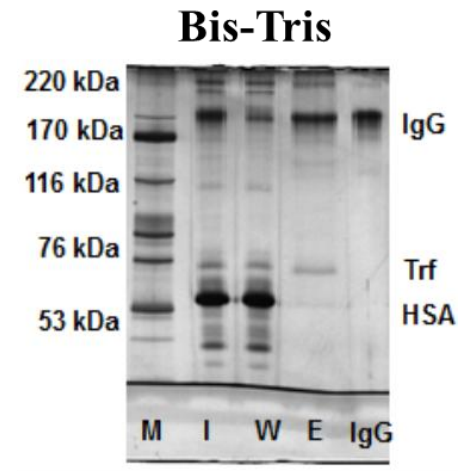

(f)

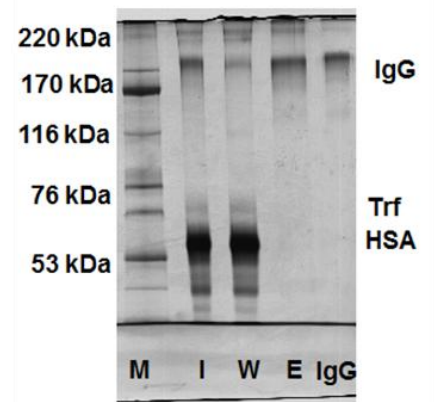

Figura 3: MES (a) $\mathrm{pH}$ 5,5 e (b) $\mathrm{pH}$ 6,5. Mops (c) $\mathrm{pH}$ 6,5 e (d) pH 7,5. Bis-Tris (e) $\mathrm{pH}$ 6,0 e (f) $\mathrm{pH}$ 7,0. Perfil eletroforético: (M) - marcador de massa molecular. (I) - solução de injeção.

(W) "Pool" lavagem. (E) - "Pool" eluição. (IgG) - marcador de IgG.

$\mathrm{O}$ aumento do $\mathrm{pH}$ resultou na diminuição da capacidade de adsorção de proteína total para os três sistemas tamponantes estudados (Figura 2), no entanto, houve o aumento da seletividade, sendo verificada maior homogeneidade eletroforética para valores maiores de $\mathrm{pH}$ (Figura 3). Desta forma, de acordo com as eletroforeses apresentas na Figura 3, as condições em que foi obtida IgG humana livre de impurezas foi nas condições Bis-Tris pH 7,0 e Mops $\mathrm{pH} 7,5$.

\section{CONCLUSÃO}

Os experimentos de adsorção demonstraram que o grupamentos fosfato e carboxílico presentes na estrutura do OPT são os principais responsáveis pela adsorção de $\operatorname{IgG}$, indicando a predominância da interação eletrostática na captura da IgG. Os resultados obtidos para os ensaios com plasma humano para o adsorvente OPT-agarose nas condições Bis-Tris pH 7,0 e Mops $\mathrm{pH}$ 7,5 podem ser empregados captura de IgG humana a partir do plasma humano, sendo observada homogeneidade eletroforética.

\section{REFERÊNCIAS}

BAYRAMOGLU, G.; SENEl, A.U.; ARICA, M.Y. Adsorption of IgG on spacer-arm and Larginine ligand attached poly(GMA/MMA/EGDMA) beads. J Appl Polym sci, v. 104, p. 672-679, 2007.

BRADFORD, M.M. A rapid and sensitive method for the quantitation of microgram quantities of protein utilizing the principle of protein-dye binding. Anal Biochem., v. 72, 
p. 248-254, 1946.

BRESOLIN, I.T.L.; FIORITTI, R.R.; BUENO, S.M.A. IgG purification by negative chromatography in amine-based ligands: A comparison of L-lysine and poly-L-lysine. Process Biochem., v. 46, p. 2277-2285, 2011.

BRESOLIN, I.T.L.; BUENO, A.M.A. Evaluation of Amino Acid O-Phosphoserine as Ligand for the Capture of Immunoglubulin G from Human Serum. Appl Biochem Biotech., v. 167, p. 632-644, 2012.

GANGNON, P. Technology trends in antibody purification. J Chromatogr. A, v. 1221, p. 5770, 2012.

HERMANSON, G.T.; MALLIA, A.K.; SMITH, P.K. Immobilized affinity ligand techniques. Academic Press: San Diego, p. 118-119, 1992.

MCLAUGHKIN, L.W.: Mixed-mode chromatography of nucleic acids. Chem Ver., v. 89, n², p. 309-319, 1989.

MORRISSEY, J. H. Silver stain for proteins in polyacrylamide gels: A modified procedure with enhanced uniform sensitivity. Anal Biochem, v. 117, p. 307-310, 1981.

NAIK, A. D.; RAINA, M.; LALI, A.M. AbSep-An amino acid based pseudobioaffinity adsorbent for the purification of immunoglobulin G. J Chromatogr A, v. 1218, p. 17561766, 2011.

TURKMEN, D.; DENIZLI, A.; OZTURK, N.; AKGOL, S.; EL-KAK, A. Phenylalanine Containing Hydrophobic Nanospheres for Antibody Purification. Biotechnol Prog., v. 24, p. 1297-1303, 2008.

VICTOR, S. P.; SHARMA, C.P. Tryptophan complexed hydroxyapatite nanoparticles for immunoglobulin adsorption. J. Mater. Sci.: Mater. Med.. v. 22, p.2219-2229, 2011.

ZACHARIOU, M.; TRAVERSO, I.; HEARN, M.T.W. High-performance liquid chromatography of amino acids, peptides and proteins. CXXXI. O-phosphoserine as a new chelating ligand for use with hard Lewis metal ions in the immobilized-metal affinity chromatography of proteins. J Chromatogr. A, v. 646, p. 107-120, 1993.

ZHANG, S.; SUN, S.: Furher studies on the contribution of electrostatic and hydrophobic interactions to protein adsorption on dye-ligand adsorbents. Biotechnol Bioeng., v. 75, $\mathrm{n}^{\circ}$ 6, p. 710-717, 2001.

ZHAO, G.; DONG, X.; SUN, Y. Ligands for mixed-mode protein chromatography: Principles, characteristics and design. J Biotechnol., v. 144, p. 3-11, 2009. 